\title{
Assessment of the Level of Anxiety and Associated Factors among Heart Patients Waiting for Cardiac Procedure at a Tertiary Care Hospital in North India
}

\author{
${ }^{1}$ Sujeet K Sinha, ${ }^{2}$ Kanika Jain, ${ }^{3}$ Anant K Verma
}

\begin{abstract}
Introduction: The anxiety experienced among patients may have various causes, including not feeling cared about as an individual, not explained by physician regarding plan of treatment, too much waiting time before the procedure begins, and the physical discomfort like not getting proper bed by the hospital authority.

Anxiety can cause behavioral and cognitive changes which can result in increased tension, apprehension, nervousness, and aggression. Some patients may become so nervous and apprehensive that they are unable to understand or follow simple instructions. Some patients may be so aggressive and demanding that they require constant attention of the nursing staff and may end up fighting with the health care provider.
\end{abstract}

Need of this study: With few public-run cardiac centers, it was always a difficult task of managing the huge patient load on limited beds by the management. Nonavailability of beds forced the clinicians to keep the patients waiting for admission on trolley or postpone the surgery. In addition, it was also noticed that the doctors did not adequately counsel the patients regarding their plan and procedure of treatment. As a result, there is always disgruntlement among the patients, resulting in increased anxiety, apprehension, and aggression.

Objective: To assess the level of anxiety of patients before the cardiac procedure as per the Hamilton Anxiety Rating Scale (HAM-A) and to analyze whether adequate time is being given by the treating physicians in counseling of the patients about the treatment plan.

Materials and methods: This is a cross-sectional study done on patients waiting for cardiac procedure in a cardiac center of a tertiary care hospital. Patients admitted on daycare basis for the procedure were also included. All the patients waiting for the procedure were assessed at the time of admission. Participants were assessed using a performa containing two parts. Part one of the performa was used to capture the demographic profile of the patients and questions related with their disease condition. The second part consisted validated HAM-A. The HAM-A is a widely used scale in both clinical and research settings. The scale consists of 14 items. Each item is scored on a scale of 0

\section{${ }^{1}$ Senior Resident, ${ }^{2,3}$ Assistant Professor \\ 1,2Department of Hospital Administration, All India Institute of Medical Sciences, New Delhi, India \\ ${ }^{3}$ Department of Psychiatry, Vardhman Institute of Medical Sciences, Pawapuri, Bihar, India}

Corresponding Author: Sujeet K Sinha, Senior Resident Department of Hospital Administration, All India Institute of Medical Sciences, New Delhi, India, e-mail: sujeet sinha20@ yahoo.com (not present) to 4 (severe), with a total score range of 0 to 56 , where $<17$ indicates mild severity, 18 to 24 mild to moderate severity, and 25 to 30 moderate to severe. These patients were then grouped as having mild, moderate, and severe anxiety based on HAM-A score.

Results: The study was carried out to find out the severity of anxiety of the patients waiting for the cardiac procedure. Total 110 patients were enrolled in the study. It was found that 63 $(70.8 \%)$ male and $9(42.9 \%)$ female patients had mild anxiety. In contrast, $4(19 \%)$ male and $5(5.6 \%)$ female participants had severe anxiety. There was statistically significant relationship $(p<0.05)$ in the anxiety level between male and female patients. Patients who were not adequately counseled by the physician were found to be suffering more moderate $(33.3 \%)$ and severe $(16.7 \%)$ anxiety in comparison with other groups.

Conclusion: There is no doubt that anxiety is very much relevant before any cardiac procedure. Counseling of the patients before any procedure plays a significant role in reducing the severity of the anxiety level.

Keywords: Anxiety, Cardiac procedure, Teaching hospital.

How to cite this article: Sinha SK, Jain K, Verma AK. Assessment of the Level of Anxiety and Associated Factors among Heart Patients Waiting for Cardiac Procedure at a Tertiary Care Hospital in North India. Int J Res Foundation Hosp Healthc Adm 2017;5(2):68-72.

\section{Source of support: Nil}

Conflict of interest: None

\section{INTRODUCTION}

Anxiety, as defined by Wilson-Barnett, ${ }^{1}$ is the fear of the unknown, disproportionate to the threat and related to the future. It is characterized by an individual's inability to specify the source of the threat. Waiting for the cardiac or surgical procedure can be a major source of stress and anxiety. These feelings are directly related to the invasive nature of the procedure and to uncertainties related to diagnosis. ${ }^{2}$ In daily practice, it is observed that patients do not understand clear instructions, or appropriate information is not provided by the health care provider. In this context of waiting and anxiety, relatives are also stressed and share feelings and uncertainties with the patients.

Evidence has indicated that properly preparing the patients and giving them some information about the procedure before surgery and invasive procedures might not only decrease their anxiety but could also increase their tolerance to deal with postoperative pain. Besides, 
it was associated with feeling a higher level of well-being and quality of life. ${ }^{3-7}$

Anxiety has been shown to lead to high levels of stress, creating delays in recovery and increased length of stay within the hospital. ${ }^{8}$ Historically, nurses have handled patient physiological needs with great confidence, but patient psychological needs, such as the manifestation of anxiety, have not received the same attention.

While searching the literature for data on precardiac catheterization and patient anxiety, it became apparent that there is very little published research on these topics. It has been noted that preprocedure psychological preparation reduces hospital-induced anxiety. Cupples ${ }^{9}$ and Martin ${ }^{10}$ both found that patients who received educational information preoperatively were shown to have less nausea, vomiting, pain, and postoperative complications, and had deceased lengths of hospital stay.

Helping patients cope with the anxiety of medical procedures is a two-way street. Health professional needs to know the type of information that is necessary and that will be of benefit, but they need to tailor this to the needs and capabilities of the individual. For the benefit of the argument, let us assume the patient is about to undergo some cardiac procedure. Five broadly overlapping types of information will be of benefit. The first of these is simple factual information about the procedure(s) and what will happen. The second is how much this will make the person feel better in terms of their senses. For example, they may want to know that it is perfectly normal to feel sick following esthetics. The third relates to any particular emotions that may be evoked and the fourth a time frame for recovery. Although not strictly related to the procedure, it is important for the patient to know how long they may be out of work as a result of their condition.

With all of these issues, effective communication is the key to helping reduce anxiety. Not all patients like to ask questions and not all know what questions to ask. It should not be assumed that silence equates to satisfaction. Neither should it be assumed that having imparted information it has been remembered or understood. Even the most relaxed and intelligent person can find themselves overwhelmed with information and terminology. As much as information can help to reduce anxiety. It must be remembered that anxiety also serves to make concentration poor and hence, block perceptibility of information. For this reason, time, careful use of language, and checking that the information is understood are essential skills for health care providers in helping patients cope with anxiety.

\section{Need of This Study}

The study was conducted in a cardiac center which is a part of a bigger tertiary care teaching hospital in North India. The center since its inception has witnessed a constant increase in the number of patients visiting its outpatient (by $23.13 \%$ ) and inpatient (by 35.79\%) department over 2 years, and the numbers of cardiac procedures have increased accordingly during the same duration. Being the few public-run cardiac centers, it was always faced with the daunting task of managing the huge patient load on limited beds. Nonavailability of beds forced the clinicians to keep the patients waiting for admission on trolley, and at the same time they did not confirm as to whether the procedure will be conducted or not on the same day. In addition, it was observed that the doctors did not adequately counsel the patients regarding the plan and procedure of treatment. This left the patient feeling uninformed and nonparticipatory in the decision of his/her treatment, which led to disgruntlement among the patients visiting the center, creating an unpleasant doctor-patient relationship.

\section{Aim}

To assess the level of anxiety and associated factors among heart patients waiting for cardiac procedure at tertiary care hospital.

\section{Objectives}

- To assess the level of anxiety of patients before the cardiac procedure as per HAM-A.

- To analyze whether adequate time is being devoted by the treating physicians in counseling of the patients about the treatment plan.

\section{MATERIALS AND METHODS}

This is a cross-sectional descriptive study done on patients waiting for cardiac procedure in a cardiac center of a tertiary care hospital. Purposive sampling was done wherein willing patients above 18 years of age awaiting the cardiac procedure were included in the study. Patients admitted on daycare basis for the procedure were also included. All the patients were assessed only at the time of admission. Patients undergoing any emergency cardiac procedure or those patients who were already admitted before in the center were not included in the study. Patients were assessed using a performa containing two parts.

Part one of the performa was used to capture the demographic profile of the patients and questions related with their disease condition. This part had questions pertaining to education level, income level, disease duration, number of visits before the current procedure, time taken for the procedure, whether the patient was explained before the procedure or not by the physician, and whether patients wish to get admitted at least 1 day prior to cardiac procedure. 
The second part consisted the validated HAM-A. ${ }^{11}$ The HAM-A is widely used scale in both clinical and research settings. The scale consists of 14 items, each defined by a series of symptoms and measures both psychic anxiety (mental agitation and psychological distress) and somatic anxiety (physical complaints related to anxiety). The reported levels of interrater reliability for the scale are good. It takes 15 to 20 minutes to complete the interview and score the results. Each item was scored on a scale of 0 (not present) to 4 (severe), with a total score range of 0 to 56 , where $<17$ indicates mild severity, 18 to 24 mild to moderate severity, and 25 to 30 moderate to severe.

The data were compiled and analyzed using Statistical Package for the Social Sciences software (version 20). It was analyzed through applying descriptive and inferential analysis, such as frequencies, percentage, mean score, and chi-square test. The 95\% confidence interval and 5\% significance level were used to evaluate the findings.

\section{RESULTS}

The current study was aimed to test the severity of anxiety in patients attending the cardiac center for cardiac intervention and was admitted for intervention on the same day. The patients were taken for procedure on same day without providing a proper bed. Such patients were not properly counseled about their plan of care by their treating physician prior to the procedure, leaving them unaware of their treatment and diagnosis. Total 110 patients were enrolled in the study. These patients were then grouped having mild, moderate, and severe anxiety based on HAM-A score.

Table 1 shows that total 110 patients participated in this study. The age distributions of the patients were as follows: 19 of the participants $(17.3 \%)$ were $<40$ years, 59
Table 1: Demographic profile of the patients

\begin{tabular}{lll}
\hline Profile & Number $(n=110)$ & Percentage \\
\hline Age (years) & & \\
$\quad<40$ & 19 & 17.3 \\
$\quad 41-60$ & 59 & 53.6 \\
$\quad>61$ & 32 & 29.1 \\
Sex & & \\
$\quad$ Male & 89 & 80.9 \\
$\quad$ Female & 21 & 19.1 \\
Residential status & & \\
$\quad$ Urban & 50 & 45.45 \\
$\quad$ Rural & 60 & 54.54 \\
Educational status & & \\
$\quad$ Illiterates & 29 & 26.4 \\
$\quad$ Up to 12th & 64 & 58.2 \\
$\quad>12$ th & 17 & 15.5 \\
\hline
\end{tabular}

of them (53.6\%) were between 41 and 60 years, and 32 of them $(29.1 \%)$ were 61 years or older. Among all the patients enrolled, maximum belonged to the cardiac vulnerable age group of 41 to 60 years, with the mean age of the patients attending the center being $52.23 \pm 14.07$ years giving us a range of 16 to 89 years. Males (80.9\%) were found visiting the cardiac center more than females $(19.1 \%)$. Not much difference in the need for cardiac care was noted among patients belonging to urban $(45.45 \%)$ or rural areas $(54.54 \%)$. It was also interesting to note that maximum patients $(58.2 \%)$ had received education up to class 12 th, which could be corroborated to the fact that maximum patients visiting the center had a rural background.

Table 2 shows the relationship between the demographic profile of the study population and the degree of anxiety. Statistically significant relationship was found between the gender and the degree of anxiety recorded. It was observed that male and female patients mostly suffered from mild anxiety (70.8 and $42.9 \%$ ) and only $38.1 \%$

Table 2: Relationship between the demographic profile and the degree of anxiety

\begin{tabular}{|c|c|c|c|c|c|c|c|c|c|}
\hline & & \multicolumn{2}{|c|}{ Mild } & \multicolumn{2}{|c|}{ Moderate } & \multicolumn{2}{|c|}{ Severe } & \multirow[b]{2}{*}{$\chi^{2}$} & \multirow[b]{2}{*}{$p$-value } \\
\hline & & $n$ & $\%$ & $n$ & $\%$ & $n$ & $\%$ & & \\
\hline \multirow[t]{3}{*}{ Gender } & Female & 9 & 42.9 & 8 & 38.1 & 4 & 19 & 7.125 & $0.028^{*}$ \\
\hline & Male & 63 & 70.8 & 21 & 23.6 & 5 & 5.6 & & \\
\hline & Total $(n=110)$ & 72 & 65.5 & 29 & 26.4 & 9 & 8.2 & & \\
\hline \multirow[t]{4}{*}{ Education level } & Illiterate & 19 & 65.5 & 8 & 27.6 & 2 & 6.9 & 6.490 & 0.16 \\
\hline & Up to 12th & 44 & 68.8 & 17 & 26.6 & 3 & 4.7 & & \\
\hline & $>12$ th & 9 & 52.9 & 4 & 23.5 & 4 & 23.5 & & \\
\hline & Total & 72 & 65.5 & 29 & 26.4 & 9 & 8.2 & & \\
\hline \multirow[t]{3}{*}{ Residence } & Rural & 49 & 59.8 & 25 & 30.5 & 8 & 9.8 & 4.652 & 0.098 \\
\hline & Urban & 23 & 82.1 & 4 & 14.3 & 1 & 3.6 & & \\
\hline & Total & 72 & 65.5 & 29 & 26.4 & 9 & 8.2 & & \\
\hline \multirow[t]{5}{*}{ Income (Rs/month) } & 0 & 2 & 33.3 & 4 & 66.7 & 0 & 0 & 9.952 & 0.12 \\
\hline & $<5,000$ & 30 & 65.2 & 14 & 30.4 & 2 & 4.3 & & \\
\hline & $5,000-10,000$ & 17 & 68.0 & 6 & 24.0 & 2 & 8.0 & & \\
\hline & $>10,000$ & 23 & 69.7 & 5 & 15.2 & 5 & 15.2 & & \\
\hline & Total & 72 & 65.5 & 29 & 26.4 & 9 & 8.2 & & \\
\hline
\end{tabular}


Level of Anxiety and Associated Factors among Heart Patients

Table 3: Clinical profile and anxiety level of patients

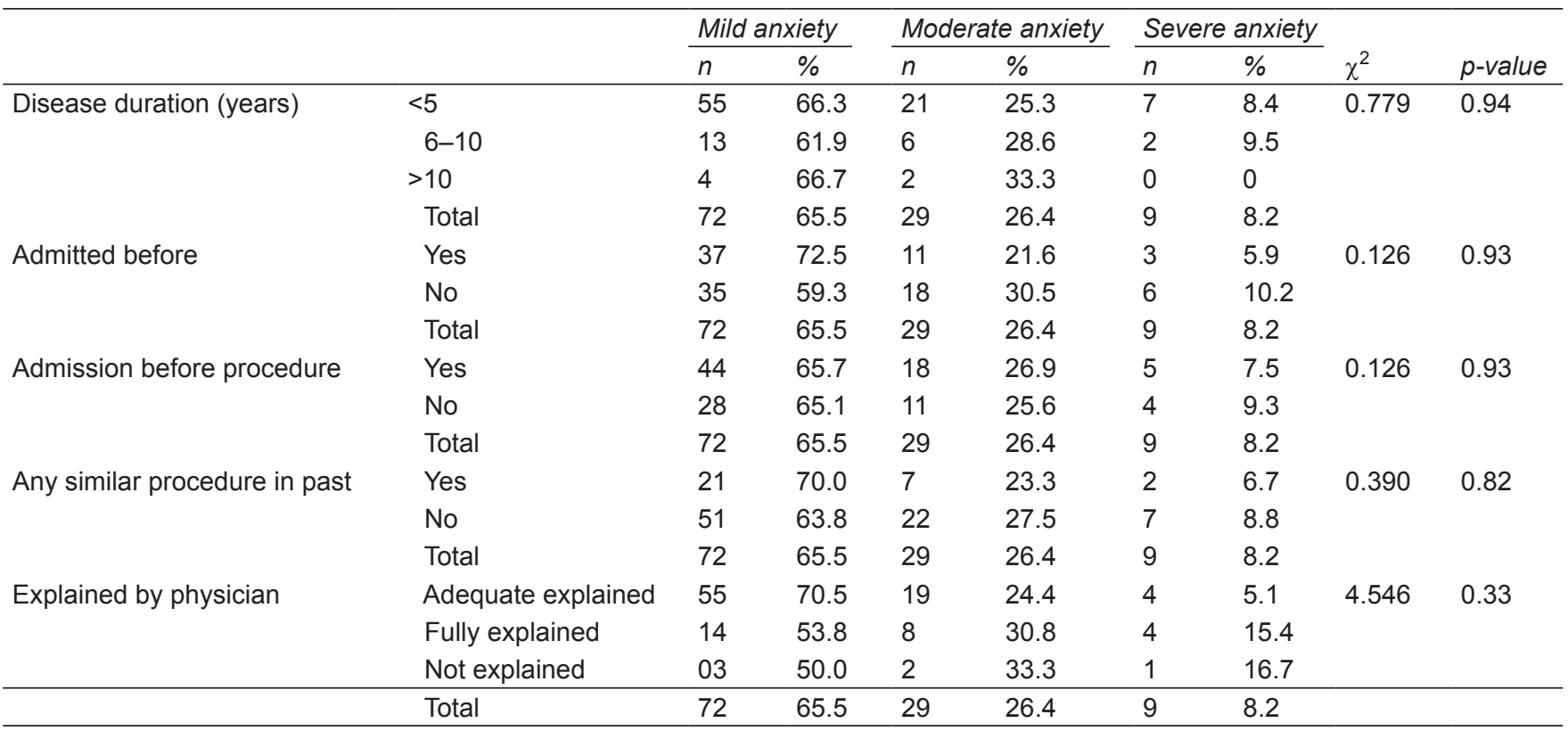

female patients were found suffering from moderate anxiety. There was no significant relationship between the level of education and degree of anxiety. However, not much difference was found in the number of patients suffering from mild and moderate degree of anxiety if their education level was taken into consideration. However, it was found that among all the patients suffering from severe anxiety, the more educated the patients, the more the anxiety was noted $(23.5 \%)$. About $82.1 \%$ patients residing in the urban area were found to be suffering from mild anxiety, and $30.5 \%$ patients residing in the rural areas were found suffering from moderate anxiety. The area of residence did not make a significant difference among the patients suffering from severe anxiety. When patient anxiety was analyzed in relation to income, it was found that $30(65.2 \%)$ patients had mild anxiety whose income level was less than Rs 5,000 per month. Fourteen $(30.4 \%)$ participants in the same income group had mild anxiety and only two patients had severe anxiety. In contrast, only 23 (69.9\%) participants had mild anxiety whose income was more than Rs 10,000 per month and $5(15.5 \%)$ patients had severe anxiety in the same income level which is maximum in all income groups.

Table 3 illustrates the relationship between the clinical profile and the anxiety level among patients. Maximum responders had been suffering from the disease for less than 5 years and among these $55(66.3 \%)$ were found to be suffering from mild anxiety, 21 (25.3\%) moderate anxiety, and 7 (8.4\%) with severe anxiety. There was no significant difference among the patients suffering from severe anxiety based on the duration of disease. Patients who were admitted for the first time were found to be more prone to moderate (30.5\%) to severe (10.2\%) anxiety in comparison with patients who have already been admitted earlier.

No significant difference was found among patients who have undergone a similar procedure in the past and those who got admission prior to the procedure in comparison with their counterparts. However, the results definitely highlight the importance of counseling by the physician; patients who were not adequately counseled by the physician were found to be suffering more moderate $(33.3 \%)$ and severe $(16.7 \%)$ anxiety in comparison with other groups, although no statistically significant relationship was found.

\section{DISCUSSION}

The study was carried out to find out the anxiety of the cardiac patients waiting for cardiac procedure.

In the present study, it is shown that the higher percentage of the sample [59 (53.6\%)] was between 41 and 60 years of age group and out of them 89 (80.9\%) were male patients.

This result is in parallel with the study that showed that according to the demographic data for patients undergoing only diagnostic cardiac catheterization procedures approximately two-thirds were male, whereas $56 \%$ of the patients were 65 years of age or older and $10 \%$ of the patients were 80 years of age or older. ${ }^{12}$

In the current study, it was observed that male and female patients mostly suffered from mild anxiety (70.8 and $42.9 \%$ ) and $38.1 \%$ female patients were found suffering from moderate anxiety. In contrast to the study done in Iran, ${ }^{13}$ it was found that women expressed greater anxiety than men. However, men and women 
were similar at all levels of anxiety in their preference for information and control. Women were significantly more anxious $(\mathrm{p}<0.05)$. Although more cardiac procedures are done in men, many studies mention that women are more affected by anxiety. According to some previous studies, the incidence in women ranged from 30 to $55 \%$. About $45 \%$ of females present mild anxiety and $40 \%$ have moderate anxiety. $2,14,15$

In the present study, it was found that 55 (70.5\%) patients had mild anxiety in spite of adequate information given by the physician before the procedure, 19 (24.4\%) had moderate, and 4 (5.1) had severe anxiety. Above results definitely highlight the importance of counseling by the physician; patients who were not adequately counseled by the physician were found to be suffering more moderate $(33.3 \%)$ and severe $(16.7 \%)$ anxiety in comparison with other groups, although no statistically significant relationship was found.

$\mathrm{Ng}$ et $\mathrm{al}^{16}$ studied the effect of preoperative counseling on the anxiety of patients undergoing oral surgery in Hong Kong. The Depression Anxiety Stress Scale was used to measure study participants' level of anxiety before surgery. The participants had statistically significant decrease in anxiety compared with the baseline measure. Our study corroborates with this study.

\section{CONCLUSION}

It is apparent from our study that counseling before cardiac procedure unquestionably reduces the anxiety level of the patients. Other factors, such as providing beds and other physical facilities to the patients further reduce the level of anxiety.

\section{REFERENCES}

1. Wilson-Barnett J. Patients' emotional reactions to hospitalization: an exploratory study. J Adv Nurs 1976 Sep;1(5):351-358.

2. Grazziano ES, Bianchi ER. Nível dea nsiedade de clients submetidos a cineangiocoronariografia eseus acompanhantes. Rev Lat-Am Enf 2004 Mar-Apr;12(2):168-174.

3. Jamshidi N, Abbaszadeh A, Najafi Kaliani M. The effects of video education on comfort and tolerability of patients undergoing coronary angiography. Iran J Nurs Res 2010 Spring;5(16):38-44.

4. Asilioglu K, Celik SS. The effect of preoperative education on anxiety of open cardiac surgery patients. Patient Educ Couns 2004 Apr;53(1):65-70.

5. Ganji T, Taleggani N, Haghani H. The effect of teaching on the level of anxiety and knowledge of patients before cardiac catheterization. Iran J Nurs 2004 Summer;17(38):51-57.

6. Moline LR. Patient psychologic preparation for invasive procedures: an integrative review. J Vasc Nurs 2000 Dec;18(4): 117-122.

7. Seyam S, Hidarnia AR, Tavafian SS. Self-care education through coping style for patients after heart surgery. J Isfahan Med Sch 2011 Jun;29(135):433-444.

8. Kempe AR, Gelazis R. Patient anxiety levels: an ambulatory surgery study. AORN J 1985 Feb;41(2):390-391, 394, 396.

9. Cupples SA. Effects of timing and reinforcement of preoperative education on knowledge and recovery of patients having coronary artery bypass graft surgery. Heart Lung 1991 Nov;20(6):654-660.

10. Martin D. Pre-operative visits to reduce patient anxiety: a study. Nurs Stand 1996 Feb;10(23):33-38.

11. Maier W, Buller R, Philipp M, Heuser I. The Hamilton Anxiety Scale: reliability, validity and sensitivity to change in anxiety and depressive disorders. J Affect Disord 1988 Jan-Feb; 14(1):61-68.

12. Dehmer GJ, Weaver D, Roe MT, Milford-Beland S, Fitzgerald S, Hermann A, Messenger J, Moussa I, Garratt K, Rumsfeld J, et al. A contemporary view of diagnostic cardiac catheterization and percutaneous coronary intervention in the United States: a report from the CathPCI Registry of the National Cardiovascular Data Registry, 2010 through June 2011. J Am Coll Cardiol 2012 Nov;60(20):2017-2031.

13. Al-Hadraawy SK, Al-qraby ME, Al-Shebly FM. Study of some parameter in men infected with Entamoeba histolytica in Al-Najaf Al-Ashraf province. J Babylon Univ Pure App Sci 2015 Nov;23(2):672-679.

14. Ulvik B, Bjelland I, Henestad BR, Omenaas E, WentzelLearsen T, Nygard O. Comparison of the short form 36 and the hospital anxiety and depression scale measuring emotional distress in patients admitted for elective coronary angiography. Heart Lung 2008 Jul-Aug;37(4):286-295.

15. Lourenci RB. Sistematização da assistência de enfermagem ao paciente submetido ao cateterismo cardíaco: análise da produção científica. Online Braz J Nurs 2006 Dec;5(3).

16. Ng SK, Chau AW, Leung WK. The effect of preoperative information in relieving anxiety in oral surgery patients. Community Dent Oral Epidemiol 2004 Jun;32(3):227-235. 